\title{
HUMOR ACADÉMICO
}

\section{SEIS INDICADORES EN BUSCA DE UN SENTIDO}

\section{Six indicators in search of a meaning}

\section{Juan Gorraiz y Evaristo Jiménez-Contreras}

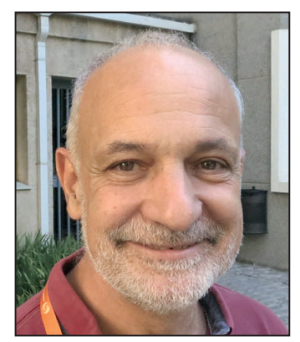

Juan Gorraiz estudió física en la Universidad Complutense de Madrid y en la Universidad de Viena, donde obtuvo su doctorado. Es director del Departamento de Bibliometría y Estrategias de Publicación del Servicio de Biblioteca y Archivos de la Universidad de Viena, que se especializa en apoyar tanto a los investigadores como a los responsables de la toma de decisiones en la administración de la investigación. Ha participado en análisis y estudios bibliométricos desde 2001. Ha estado enseñando recuperación de información y bibliometría en los estudios universitarios de Biblioteconomía e Información desde 1992. Además de su continuado compromiso con la Escuela Europea de Verano de Cienciometría, fue organizador y presidente del programa de la 10a conferencia internacional Science \& Technical Indicators de 2008 en Viena, así como uno de los organizadores de la 14a conferencia de la Int/ Society of Scientometrics y Informetrics (ISSI) en 2013, también en Viena.

http://orcid.org/0000-0002-2414-3212

University of Vienna, Vienna University Library, Bibliometrics and Publication Strategies Boltzmanngasse 5, A-1090 Vienna, Austria juan.gorraiz@univie.ac.at

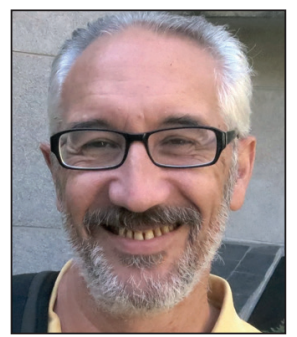

Evaristo Jiménez-Contreras es catedrático de bibliometría en la Facultad de Comunicación y Documentación de la Universidad de Granada, y director del Grupo de investigación EC3 (Evaluación de la Ciencia y de la Comunicación Científica). Sus líneas de investigación se centran en la evaluación de la actividad científica con metodología bibliométrica. Es uno de los promotores de los índices de impacto de las revistas españolas de ciencias sociales, jurídicas y humanas In-Recs, In-Recj, InRech, CIRC (Clasificación integrada de revistas científicas), Metaranking EC3 y Científica. http://orcid.org/0000-0001-5668-7057

Universidad de Granada, EC3 Research Group Campus Cartuja. 18071 Granada, España evaristo@ugr.es

\section{Resumen}

Esta contribución es una especie de documento conceptual y a la vez una reflexión, pero también algo más, un acto de provocación en forma de una pieza de teatro que muestra una realidad, algo dramática y cómica a la vez, como es el panorama de nuestra investigación. También incluye una buena porción de humor, pero de ese tipo de humor que el gran escritor y pensador Luigi Pirandello definiera como "el que no provoca la inmediata carcajada, sino sólo arranca una sonrisa detrás de la cual se esconde el amargo sabor de lo absurdo o la insoportable levedad de nuestra existencia". Esta pieza de teatro, corta y concisa para no aburrir a nadie, narra los esfuerzos que se requieren a diario y las tramas que se originan para llevar a cabo esa tarea -que es más bien utopía- de intentar medir algo que es inconmensurable, como lo es la ciencia por parte de quienes nos dedicamos a su evaluación o al estudio de su desarrollo. En ella, todos los actores involucrados, tanto los protagonistas como los propios indicadores, tienen oportunidad de presentar sus esperanzas y sus miedos, sus méritos y sus quejas, sus recomendaciones y advertencias, y narran la búsqueda de un camino en esa jungla en que se ha convertido el mundo de la información que sea practicable, augure un futuro prometedor a la ciencia y nos permita a nosotros una más justa interpretación.

\section{Palabras clave}

Evaluación científica; Medición de la ciencia; Revisión por pares; Cienciometría; Indicadores; Política; Factor de impacto; Índice h; Indicador Crown; Indicador de Gini; Altmétricas.

\footnotetext{
Abstract

This is a kind of conceptual document, and at the same time a reflection, but also something more, an act of provocation in the form of a piece of theater that shows a reality, something dramatic and comical at the same time, as is the panorama of
} 
our research. It also includes a good portion of humor, but the kind of humor the great writer and thinker Luigi Pirandello defined as "the one that does not provoke the immediate laughter, but only pulls a smile behind which hides the bitter taste of the absurd or the unbearable lightness of our existence." This piece of theater, short and concise so as not to bore anyone, narrates the efforts that are required daily, as well as the situations created, to carry out the task -which is perhaps a utopia- of trying to measure something that is incommensurable, as is science on the part of those who are dedicated to its evaluation or to the study of its development. In this comedy, all actors involved, both protagonists and the indicators themselves, have the opportunity to present their hopes and fears, their merits and their complaints, their recommendations and warnings. They narrate the search for a path in a jungle in which the world of information has been converted, that is practicable, augurs a promising future for science, and allows us a more just interpretation.

\section{Keywords}

Science evaluation; Science measurement; Peer review; Scientometrics; Indicators; Policy; Impact Factor; H index; Crown indicator; Gini indicator; Altmetrics.

Gorraiz, Juan; Jiménez-Contreras, Evaristo (2018). "Seis indicadores en búsqueda de un sentido". El profesional de la información, v. 27, n. 2, pp. 432-440.

https://doi.org/10.3145/epi.2018.mar.22

\section{Introducción}

a) Presentación de los actores:

Bibliómetra
Evaluador
Científico
Director de la obra, un político responsable de
científica
Dueño del teatro, un empresario con responsab
presupuestarias
Par, un anciano calvo y de largas barbas blancas
Filósofo

Todos ellos podrían ser de los dos sexos, según se mire. Por un lado, parecen ser mujeres, pero, por el otro, cuando se dan la vuelta son hombres. El Par es un anciano/a de largas barbas blancas.

b) Presentación de los indicadores

Eugenio = Impact Factor en honor a su inventor Eugene Garfield

Jorge = Índice $\mathrm{h}$ en honor a su inventor Jorge Hirsch

MC = Mr. Crown, primer heredero de la Orden de los Normalizados

T10 = Su sobrino más repelente, el percentil top 10\%, pero no el más pequeño (ese es el top1\%)

Corrado = Indicador Gini, introducido por Corrado Gini AS = uno de los mejores representantes de la nueva dinastía de los Scores a la que pertenecen, el "Altmetric Score", el "ResearchGate Score", y muchos otros que están al llegar...

c) Las Musas o Ninfas

BD = Bella Durmiente (sleeping beauty)

$\mathrm{EA}=$ Estrella Ascendente (rising star)

d) El coro de la discordia = no hace falta, sino se convertiría en una tragedia griega, lo que no es el propósito de sus autores, aunque bien visto... no estaría tampoco mal.

\section{Obra de teatro en tres escenas precedidas de preámbulo}

"Quando un personaggio è nato, acquista subito una tale indipendenza anche dal suo stesso autore, che può esser da tutti immaginato in tant'altre situazioni in cui l'autore non pensò di metterlo, e acquistare anche, a volte, un significato che l'autore non si sognò mai di dargli!"

\subsection{Preámbulo}

\section{Escenario}

Un despacho de algún ministerio, con legajos tirados por todas partes y mucho polvo.

Empresario: -Amigo mío, usted no lo entiende, cree que los espectadores quieren más ciencia, que se invierta en investigación, pero no es verdad, no quieren más ciencia, bueno sí, la quieren, pero de un modo abstracto. Lo que quieren de verdad es una carretera que pase por su pueblo y un hospital a la vuelta de la

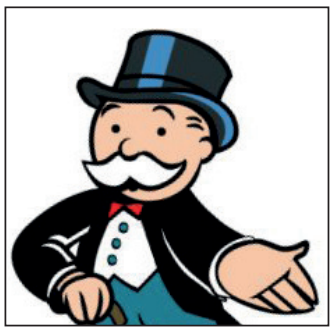

Empresario, dueño del teatro esquina. Quieren ayudas sociales, becas para sus hijos y medicamentos lo más baratos que sea posible. Si les pone en la tesitura de elegir perderá siempre esa elección al menos en cuestión de mayorías...

Político: -Pero debemos cambiar esa mentalidad, debemos convencerles de que nuestra obra, la inversión en ciencia produce beneficios, amplía nuestro conocimiento de la naturaleza, nos ayuda a entender lo qué somos, quiénes somos, de dónde venimos...

Empresario: -El mismo rollo de siempre...

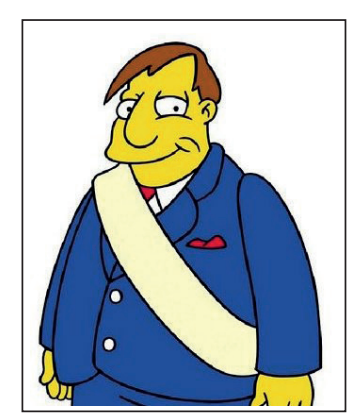

Político 
Dice el Dueño bostezando. Pero el director no se deja desanimar y continúa...

Político: -Además debemos verla como una inversión no como un gasto. Nos traerá mejores tratamientos, combustibles más eficientes, tecnología más segura, comunicaciones más rápidas y efectivas. ¿No es suficiente con ver el progreso alcanzado en las últimas décadas, no ha sido suficientemente vertiginoso? Debemos convencer a nuestros espectadores de que hay que invertir más dinero y de forma más estable, como una política a largo plazo. Yo, en realidad, ni siquiera quería hablar de esto, de lo que quiero hablar es de cómo podemos hacerlo de forma más justa y eficaz, con el mayor aprovechamiento de los fondos que tenemos.

Empresario: -No me tiene que convencer a mí, sino a ellos (y señala al patio de butacas) y si no lo hace, yo no puedo ayudarle porque me arruinaría. Quizá (añade pensativo) hayamos vendido mal la importancia de la ciencia, no tengamos una tradición asentada y, por eso, a los científicos se les ve como unos funcionarios más que gastan demasiado en cosas de dudosa y lejana utilidad. Otros vendrán, quizá, más adelante, que consigan más recursos. Pero no se engañe, siempre será a costa de sustraerlo de otra parte. El dinero es como la energía, que está sujeta a la ley de la conservación.

Político: -Pero en otros escenarios en Europa las inversiones son mucho mayores, casi duplican a las nuestras, así se consiguen mejores instalaciones y grandes avances. Incluso en períodos de dificultad o de crisis nunca se reducen estos presupuestos.

Empresario: -Estoy de acuerdo, yo le comprendo, pero es lo que hay. Tenemos que apañarnos con lo que nos dan y repartirlo lo mejor posible.

Político: -De acuerdo, empecemos entonces, porque yo tengo además otro problema, tengo que repartir lo poco que me da ("miserable", susurra por lo bajo) entre los actores. Todos quieren siempre más, todos son los mejores (según ellos mismos), su investigación es siempre crucial y, para colmo de males, ni el filósofo me ayuda, porque según él todo es relativo; ni tampoco el del sindicato de actores, porque, según él, lo que debemos hacer es repartir de forma igual los recursos.

¡Qué empiece el teatro!

Final del preámbulo

\subsection{Escena 1}

\section{Escenario}

El Director de la obra entra en una sala de mil espejos en la que las actitudes y hábitos de todos los actores se reflejan también en los demás como en la fábula japonesa "La sala de los mil espejos". Los espejos son grandes y curvos, algunos convergentes y otros divergentes. Es decir, a medida que van pasando los actores por delante de cada uno de ellos, su imagen se deforma, mostrando una versión caricaturesca de ellos.

Filósofo: -Señores, señores, para que este encuentro tenga algún sentido, les recuerdo que debemos intentar explicar y comprender los motivos y las necesidades de cada uno de nosotros. Igualmente, debemos de fijar una terminología común, para que todos nos podamos entender. Recuerden que el lenguaje no es más que fijar un conjunto de reglas para poder entenderse.

Político: -Bueno, pues empezaré yo. Para mí, es de gran

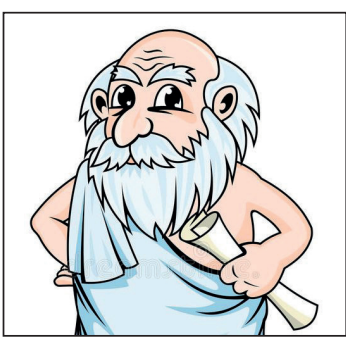

Filósofo necesidad saber quiénes son los mejores, para así poder distribuir con acierto y sentido nuestros presupuestos, que no son ilimitados. Es decir, queremos, por un lado premiar a los mejores, y por otro lado invertir en aquellos que más prometen y más se lo merecen. Para eso contamos con la ayuda de todos ustedes y especialmente de usted ¿verdad? (se dirige al evaluador).

Evaluador: -Para ello tenemos una receta increíble, que consiste en una mezcla de las opiniones de nuestros sabios o expertos universales, como por ejemplo Par (mirando a $P R$ ), y del análisis de nuestro Bibliómetra, es decir, una mezcla de objetividad y subjetividad. ¿Qué más se puede pedir?

Filósofo: -iProtesto! Hay un montón de limitaciones. Nunca se puede decir quién es el mejor...

Par: -Yo creo que sí, aunque claro que me puedo equivocar. Pero lo malo es que estoy en crisis permanente. Siempre triste, buscando al otro par que me dé la razón y no me lleve la contraria.

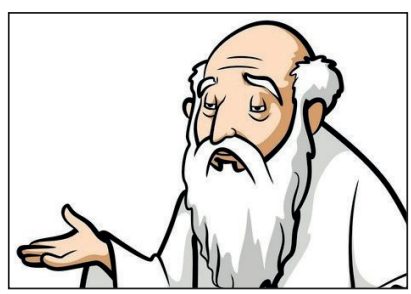

Par
Filósofo: -Y además que es muy difícil no dejarse influir por los buenos y antiguos amigos, diga usted la verdad.

Par: -Y muy ocupado, cada vez se me requiere más y no doy abasto. En esta jungla se pierde la orientación fácilmente y es muy difícil adentrarse en algunos terrenos sin hacer el ridículo.

Mi tristeza además se agranda al ver la baja calidad de lo que se me presenta. Se publica demasiado, y algunos no han consultado siquiera lo que ya está publicado. Eso me deprime mucho...

Evaluador: -iQuién te ha visto y quién te ve! Te estás volviendo viejo...

Par: -Tal vez tengas razón y sea necesaria una generación joven, innovadora y más de acuerdo con las necesidades de nuestro tiempo.

Filósofo: -...pero también vuestros comentarios se vuelven cada vez más insulsos, parece incluso como si no hubierais entendido lo que habéis leído. Deberíais tener la humildad de decir, "eso no lo entiendo"... y "no lo puedo juzgar"...

Bibliómetra: -Son quisquillosos y desconfiados por naturaleza, siempre sacando defectos. Tendrían que ser más constructivos como somos nosotros...

Par: -Calla, calla, que vuestra pedantería es extrema. ¡Exa- 
geráis con vuestros números y rankings!

Evaluador: -Bueno de eso ya me ocupo yo, de resumirlo y de volverlo comprensible.

Bibliómetra: -Sí, pero se te olvida considerar las limitaciones de cualquiera de nuestros análisis, que son una de las partes más importantes de nuestro mensaje. Es como

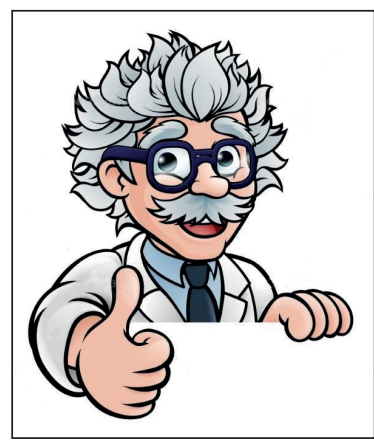

Bibliómetra leer el texto sin dar importancia a las notas a pie de página. Nuestra misión no es más que auscultar, para encontrar regularidades e irregularidades, para revelar síntomas, y luego plantear preguntas. La evaluación os la dejamos a vosotros.

Evaluador: -Siempre la peor parte, las más difícil y la más ingrata. $Y$ vosotros mientras a divertiros con vuestras correlaciones, que es vuestro vicio...

Bibliómetra: -No niego que alguno de nosotros se pase con ellas, pero son tan fáciles de hacer y quedan tan chulas...

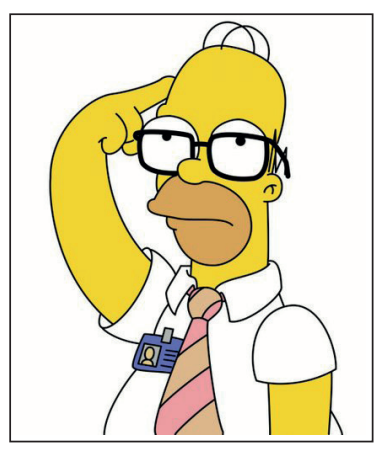

Evaluador
Filósofo: -Lo que más os gusta.., isé sincero y confiésalo...!

Bibliómetra: -Si te refieres a descubrir un nuevo indicador, es verdad que es uno de los sueños de cualquiera de nosotros.

Científico: -¡Como si no tuviéramos ya bastantes! ¡De algunos de ellos hay ya más de cien versiones! ¡Nos estáis saturando!

Evaluador: -Cierto, algo de razón llevan en sus quejas.

Científico: -Pues claro, pero nuestra opinión parece no servir a nadie. Somos como los esclavos, a trabajar y callar. Pero deberíais ser más responsables, y pensar que vuestras prácticas también afectan a nuestras culturas de publicación y crean nue-

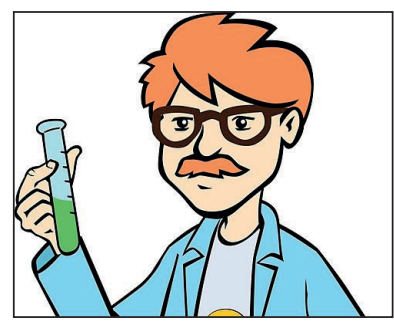
vos hábitos. Algunos de ellos pueden ser muy nocivos e, incluso, irreversibles.

Filósofo: -El acto de medir perturba al objeto, un problema filosófico bien conocido.

El filósofo se mira en uno de los espejos y su imagen se agranda, pero también se deforma.

Científico: -El ya conocido como principio de incertidumbre.

Director: -La incertidumbre la tenemos siempre nosotros. Por eso, para nosotros, contra más sencillo y comprensible sea el modelo mejor.
Bibliómetra: -Por supuesto, isi es que no os enteráis ni de la mitad de lo que hablamos, por eso sois tan peligrosos!

Filósofo: -Hacer sencillo un problema tan complejo. Eso ya es bastante contradictorio.

Empresario: -¿Contradictorio o dialéctico?

Director: -También tenéis que entendernos, se trata de un problema práctico. Al final estamos obligados a tomar decisiones, y los recursos no son ilimitados. Por eso queremos ser lo más justos posible, y recompensar a los buenos, a los mejores, y no premiar a los que no se lo merecen.

Filósofo: -Lo importante es que dejéis de emplear la palabra calidad cuando se trate de métodos cuantitativos. Se miden otras facetas, como la actividad, visibilidad e impacto. Podéis premiar a los más activos, más visibles o con mayor impacto.

Bibliómetra: -Sí pero tampoco se debe olvidar que existe un vínculo entre ambas cosas, y ahora no se trata sólo de una mera correlación, sino de una probabilidad.

Director: -Ponga un ejemplo para que le entendamos.

Bibliómetra: -Por ejemplo, la probabilidad de que una publicación muy citada sea de alta calidad es muy grande, sólo hablamos de probabilidades... pero éstas son irrefutables.

Evaluador: -Sí, se pueden usar como índices. Si una publicación no se cita, ni se lee, ni se descarga, ni se discute o menciona, ¿qué valor tiene entonces para la comunidad?

Político: -Y la pregunta más importante: ¿̇merece la pena que la paguemos? ¿Hasta cuándo vamos a poder seguir financiándolas?

Bibliómetra: -Sí, pero es que ni siquiera el medir esas cosas es tan sencillo. Piensen, por ejemplo, en la medida de la actividad de publicación, que parecería una de las más simples de asesorar. El problema de la autoría.

Evaluador: -Autor es quien firma el trabajo o su publicación.

Bibliómetra: -Pero, ¿todos los que firman son iguales?, y ¿da igual cuántos sean? Por supuesto que no, no todos aportan la misma contribución y, además, no todas las publicaciones son del mismo tipo.

Filósofo: -Indudablemente todos contribuyen al conocimiento, pero hoy en día se publica más rápido de lo que se piensa, como ya dijera uno de nuestros laureados...

Evaluador: $-Y$ lo que es peor, todos intentan aumentar su actividad, aunque para ello tengan que echar mano de prácticas bastante oscuras, cuando no fraudulentas.

Científico: -Es normal que los científicos se defiendan y se intenten ayudar, ofreciéndose coautorías.

Evaluador: -Mientras que no sean regaladas...

Científico: $-\dot{¿} Y$ no es eso una constante de nuestra sociedad actual, en la que las actividades en la red son más importantes que las cualidades de las personas?

Filósofo: -Es verdad, pero el mundo de la ciencia no puede ser menos corrupto. Es bastante inocente pensar que la ciencia pueda escapar a las reglas de nuestra sociedad, que piensa sólo en el beneficio que se produce, y en la que los 
débiles, por muy honrados y sabios que sean, se ven absorbidos y manipulados por los más poderosos. La ciencia siempre ha sido jerárquica y no le queda más remedio que reflejar los defectos de la sociedad y de su entorno.

Empresario: ¡Ay Dios!, llevamos años dándole vueltas a lo mismo.

Bibliómetra: -Pero el caso es que disponemos de un montón de indicadores para paliar esos problemas. ¿No será mejor que nos asomemos a ese mundo y escuchemos lo que nos ofrecen nuestros indicadores...? Algo aprenderemos de ellos...

\subsection{Escena 2}

El mundo del conocimiento estaba antes encerrado en los libros y las bibliotecas. Hoy en día se ha convertido en una jungla, parte de una red virtual, donde:

- las publicaciones se pueden comparar a árboles;

- las frutas son las citas que producen;

- las raíces, las referencias que citan;

- las hojas, las vistas y descargas que obtienen;

- las flores, las menciones que reciben en dicha red.

En un claro de la jungla, y sentados alrededor de una hoguera donde se cuecen algunas habas, están los seis indicadores. El mayor de ellos, Eugenio está vestido como un arlequín, con un sombrero que representa los cuatro cuartiles. Delante de ellos, juegan, se divierten y cuchichean Bella Durmiente y Estrella Ascendente.

Los actores (Filósofo, Bibliómetra, Evaluador, Científico, Político, etc.) les escuchan escondidos detrás de unas ruinas, que podrían ser las de la Biblioteca de Alejandría.

Eugenio: -Sin duda, soy yo el más mayor de todos vosotros, y lo que no veréis con buenos ojos, el más popular de todos. Sin exageración alguna, puedo decir que en mi tierna juventud revolucioné el mundo de la comunicación científica. Puse en jaque primero a todos los editores y después a toda la administración universitaria. Todos los editores científicos me acosaban e inten-

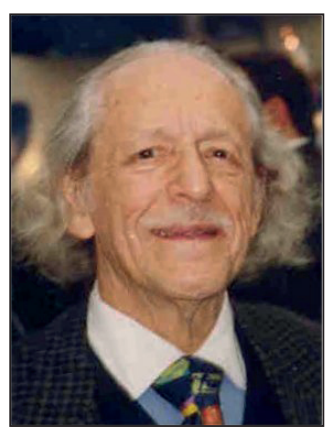

Eugene Garfield (1925-2017) taban retratarse a mi lado. ¡A la de fiestas que me han invitado! ¡Y cómo me han agasajado! Siempre querían que me mostrara con mis mejores ropas a su lado, y si faltaba causaba gran agravio y malestar.

Bella Durmiente -Sí, aunque no seas el más perfecto de todos.

(Dirigiéndose a Estrella Ascendente y riéndose) -¿ Recuerdas su falta de simetría innata desde su nacimiento, plasmada en ese ojo bizco que tiene?

Estrella Ascendente: -No se puede negar que provocó una

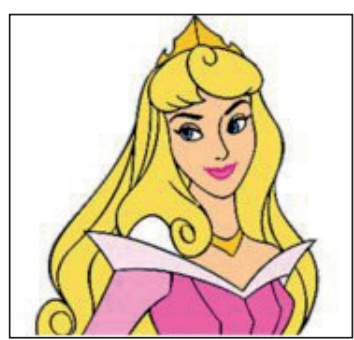

Bella durmiente gran revolución. Y a pesar de su edad, es al que más se sigue usando, aunque le hayan tenido que dar un par de toques cosméticos, para corregir varias de sus taras y volverle más robusto. $Y$ ya tenga una larga familia de descendientes y allegados, la familia IMIR (Indicadores para la medida del impacto de las revistas).

Eugenio: -No sólo eso. Mi nombre causó impacto en el sentido más literal de la palabra, y se puso de moda en el mundo de la comunicación del conocimiento.

Bella Durmiente: -Bueno, no presuma tanto, que es también el que ha sido peor empleado de todos. Hasta se han hecho declaraciones en tu contra.

Eugenio: -Ese no es mi problema. Allá ellos si no me usan para lo que estoy hecho. Soy una medida para las revistas y me identifico con ellas. No digo nada sobre el impacto de la publicación misma, pero sí sobre su mayor o menor visibilidad, si así se le quiere llamar.

Jorge: -Yo soy mucho más joven. Y al principio la comunidad bibliométrica no quiso ni siquiera considerarme, ya que ponían incluso en duda mi naturaleza de indicador.

Fueron los científicos y los evaluadores los que empezaron a usarme y lograron mi implantación. Soy consciente de todos mis defectos y carencias.

Estrella Ascendente: -Es verdad, Jorge no deja de crecer, tiene una enfermedad incurable. Además lo hace a diferentes velocidades. En compañía de los jóvenes mucho más despacio que con los mayores.

Bella Durmiente: $-Y$ lo malo es que incita a publicar desmesura-

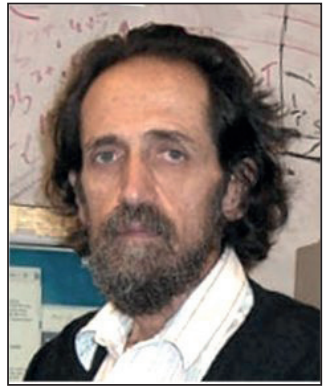

Jorge Hirsch (1953-)

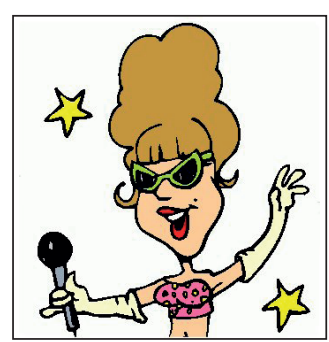

Rising star damente sin consideración de las diferencias entre disciplinas.

Mr. Crown: -Por eso mismo, la fama y reputación de mi estirpe y familia. Somos nosotros los que dimos sentido a una existencia aleatoria, basada en meros números, sin ningún sentido al no ser comparables.

Percentil top 10\%: -Y no fue fácil calcular y proveer de datos de referencia para cada una de las disciplinas, para cada año de publicación y cada tipo de documento.

Mr. Crown: -Calla y no me interrumpas, siempre igual de impertinente este sobrino, que se cree que todo lo sabe mejor.

Percentil top 10\%: -Mejor no, pero yo aporto una información más correcta, al considerar la falta de simetría inherente a todos los procesos de comunicación. Vuestra vara de medir, el valor medio, se ha quedado anticuada, tanto como vuestra mentalidad. iYa es hora de que dejéis paso a las nuevas generaciones de indicadores, la familia de los percentiles!

Bella Durmiente: -Se le están subiendo los humos a estos chicos jóvenes, como si estuvieran libre de sesgos y otros 
defectos. Y fijándose uno bien, a nosotras mismas no nos consideran normalmente...

Estrella Ascendente: - $Y$ nosotras también se la jugamos, al menos de vez en cuando.

Bella Durmiente: - $Y$ también tienen otras riñas familiares, que escuecen y pretenden ocultar lo más posible. Se creen mejores que todos los demás al considerar la asimetría innata a nuestro mundo, pero ellos son al final dependientes, por no decir, esclavos de las clasificaciones y de los niveles jerárquicos donde se estén usando.

Estrella Ascendente: -Así es, pueden ofrecer diferentes rostros según como se defina su entorno. $Y$ además, ninguno de ellos es realmente significativo.

Percentil top 10\%: -Bueno, yo soy el más usado y el que tengo más reputación. A mi hermanito, el más bajito de todos, Top1, sólo le usan realmente para identificar a los atípicos, algunos degenerados de vuestra especie (y señala con algo de sarcasmo a BD y EA).

Corrado: -Aunque Eugenio diga otra cosa, yo soy el más viejo de los indicadores, sólo que no nací para estos menesteres de la evaluación, sino, hace unos cien años, para medir la desigualdad en el reparto de la riqueza. Lo curioso es que la desigualdad en la riqueza se reparte de manera similar a la desigualdad en todos los procesos de la información, y también en la eminencia científi-

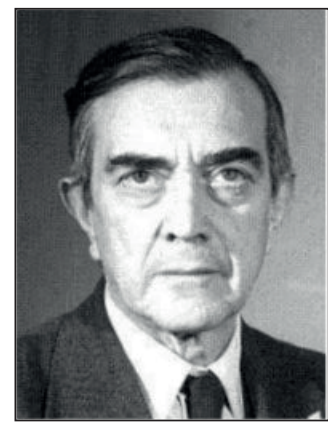

Corrado Gini (1884-1965) ca. Soy compatriota de Wifredo Pareto, que fue el primero que se preocupó de estos problemas y cuyo principio o regla del $80 / 20$ es la "noble" estirpe a la que pertenezco. Aquí, en este entorno, más parezco un emigrante ilegal al que se puede utilizar para muchas cosas, aunque, la verdad, no soy tan famoso como Eugenio en estos gremios, pero al menos tampoco se meten tanto conmigo.

Eugenio: -He de reconocer, viejo amigo, que yo también me basé en una de tus aplicaciones para identificar a las revistas fundamentales que harían posible la creación del primer índice de citas multidisciplinario.

Corrado: -Ya lo sé, en el fondo todos nos utilizan, pero a la chita callando, y nadie nos cita, como si fuéramos ya una parte del conocimiento universal.

Eugenio: -Bueno, pero es que yo luego profundicé mucho más. Tienes que reconocer que no eres suficiente para analizar el impacto a ninguno nivel, ni el individual siquiera, lo que te quita mucho interés.

Corrado: -iCuidado que tú tampoco! Y además, eso es lo que me concede interés, lo que pasa es que todavía, a pesar de mis años, no se han dado cuenta. Los políticos están demasiado volcados hacia los individuos y los bibliómetras les siguen. Parece que nadie se da cuenta de que la ciencia es cada vez más colectiva.

Percentil top 10\%: -Sí pero el reconocimiento sigue siendo individual. Los científicos son como "divas" o "prima donnas".

Corrado: -Quizá sea hora de pensar en cambiar esto. No podemos concebir la ciencia como un medallero olímpico.

Altmetric Score: -En el fondo, ya me aburrís con vuestro discurso. Sí, sobre todo vosotros dos, Eugenio y Jorge, no os olvidéis de que todo el auge mío se debe a los abusos que se han cometido en vuestro nombre.

Eugenio: -iCómo si no lo hubiéramos advertido anteriormente! Pero nadie nos hace caso.

(Defendiéndose del ataque) Ese mal uso nunca ha sido nuestro propósito y esas declaraciones de algunos listillos no serían ni siquiera necesarias. En el fondo cualquier indicador puede ser mal usado.

Altmetric Score: -De todas formas es innegable que la comunidad estaba cegada con el mundo de las citas, ese mundo al que le abriste tú las puertas, Eugenio...

Eugenio: - $Y$ que nos ha ayudado a comprender muchas cosas. El valor de las citas, a pesar de todas sus limitaciones y de todas las críticas, es incontestable. Y te diré más, querido AS, tú has venido incluso a confirmarlo.

Altmetric Score: -No os habéis dado cuenta de que una nueva era, la digital, llegaba. Pensabais que el mundo seguía encerrado en documentos y no comprendíais el nuevo mundo virtual que se abría a nuestros pasos. Todo ese nuevo abanico de medidas que se pueden recopilar hoy en día de manera automática y nos proporcionan una vista mucho más global, como menciones, discusiones, comentarios en los medios sociales.

Jorge: -Sí, pero no deja de ser paradójico que contigo se estén repitiendo los mismos errores que con Eugenio. No nos criticabais a nosotros tanto, y hablabais tanto de los efectos perjudiciales que hemos tenido en el mundo de la ciencia, y ahora te coronas tú con los mismos fallos.

Eugenio: -Los mismos, no. Son incluso mucho más aberrantes y más peligrosos. Tu origen y tu apariencia, así como el de todos tus sucesores o emuladores, carecen de transparencia, en ti se aúnan rasgos diferentes, es como sumar naranjas con manzanas, y al final, como si fuera magia negra, resulta que con una sola moneda se intenta dar una imagen completa de algo que no existe o no se puede definir.

Bella Durmiente: -Algo de razón lleva Eugenio, su uso puede ser mucha más dañino que el de los que ellos mismos pretendían combatir. La famosa, por no decir tétrica, rosquilla está ya presente por todos los

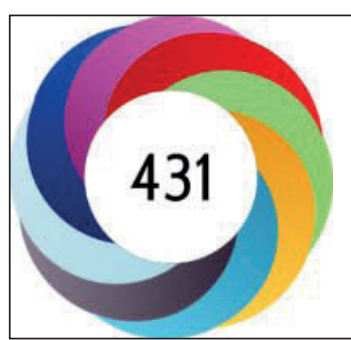

Dónut altmétrico lados y rincones.

Corrado: (por lo bajini) -Ves, si es lo que yo decía, hay que pasar de los individuos a las instituciones, son como niños...

Altmetric Score: -No falta algo de envidia, soy el nuevo as o el comodín, y eso no me lo podéis perdonar. Nosotros también recalcamos que sólo medimos la atención recibida en 
nuestro entorno virtual y no tenemos nada que ver con la calidad, ni siquiera el impacto.

Bella Durmiente y Estrella Ascendente juegan juntas delante de un espejo que lleva colgado una etiqueta enorme que reza "Bibliometría".

Bella Durmiente: -En el fondo todos ellos podrían ser los enanos de un cuento de hadas con nombre científico (le dice a EA señalando con el dedo al grupo de indicadores).

Estrella Ascendente: -A ver, espejito mágico, dime ¿quién es el mejor y el más guapo de todos?

Los seis indicadores se cogen de la mano y se dirigen hacia el público:

Todos juntos: - ¡Pedimos respeto y justicia! ¡Todos estamos deprimidos y frustrados ya que no nos tratan como nos merecemos!"

De pronto sale de su escondite el Bibliómetra y dirigiéndose al público dice:

Bibliómetra: -Los indicadores sólo pueden decirnos quién es el más alto, quién el más gordo, el más veloz y el más perezoso... pero nunca quién es el mejor...

Evaluador: -¿Y de qué nos sirve entonces? (saliendo poco a poco todos los actores de su escondite).

Bibliómetra: -Pero, naturalmente, las posibilidades de que el más grande y más veloz sea el mejor y llegue antes, por ejemplo, son muy grandes... Lo que es indudable es que ellos nos pueden ayudar a lograr una descripción objetiva de los hechos y a orientarnos en esta jungla salvaje... que es el mundo del conocimiento. También sirven para revelar síntomas que nos ayudan a plantear preguntas, necesarias para cimentar interpretaciones sólidas. Pero los síntomas no son siempre evidencia y deben ser discutidos en profundidad y en su contexto...

Cae de forma abrupta el telón.

\subsection{Escena 3}

Filósofo, Bibliómetra, Evaluador, Científico y Político se abren paso por entre una jungla donde nuestros protagonistas o actores están obligados a tener que orientarse para poder sobrevivir y tomar decisiones correctas. Intentan ayudarse con las pistas que les han dado los indicadores. Cansados se sientan a refrescarse y comer algo.

Bibliómetra: -Es verdad que hace unas décadas sólo podíamos asesorar el rendimiento científico a través del número de publicaciones...

Evaluador: -Lo que ayudó mucho a desarrollar prácticas fraudulentas, como el fraccionamiento artificial de las publicaciones...

Científico: -Y qué otra cosa íbamos a hacer (responde mientras se corta un par de rodajas de un buen salami y se las come saboreándolas).
Evaluador: -Y el problema de la autoría, en un mundo donde el número de coautores empieza ya a sobrepasar al número de palabras escritas en la publicación en algunas disciplinas. De la ciencia pequeña, hemos pasado a la grande, y hoy vamos camino de la gigante, en la que las individualidades perderán cada vez más su protagonismo.

Bibliómetra: -Luego llegaron las citas. Lo importante ya no era sólo la cantidad de las publicaciones sino el impacto que producían en la comunidad académica.

Filósofo: -Es más, para muchos siguen siendo bibliometría y análisis de citas sinónimos, lo que no es correcto. En su definición se postula, sin embargo, el uso de cualquier medida cuantitativa para analizar y describir diferentes aspectos del mundo de la comunicación o información, y se le llama ahora de manera más amplia "informetría".

Bibliómetra: (Sarcásticamente) -¿̇lnformetría? Eso nadie lo utiliza. Mi nombre sigue siendo, para bien o para mal la referencia para todos lo que se acercan a este mundillo.

La nueva era online y digital trajo un renacimiento de las medidas de uso, que dejaron de ser tarea ardua y meticulosa de los bibliotecarios para convertirse en datos que se podían recolectar de manera simple, rápida y automática. Aparecieron dos indicadores: el número de vistas y el número de descargas. Pero ambas siguen siendo parte de mi mundo, dos visiones más...

Evaluador: -Lo que son buenas noticias, son medidas complementarias que pueden ayudar a proporcionar un análisis más completo de la resonancia que han tenido las publicaciones.

Bibliómetra: -Sí, pero son un tipo de indicadores aún más complejos y controvertidos que las citas.

Político: -El problema es que se pueden manipular fácilmente.

Bibliómetra: -Como todo, eso se puede controlar. Se podría contar el número de usuarios distintos que han ejecutado esas vistas o descargas, lo que permite eliminar manipulaciones...

Filósofo: -No se debe de olvidar de las manipulaciones también se producen en las citas, donde no siempre se cita lo que se debería; algunas veces porque se desconocen y otras por motivos menos honorables, como son el no reconocer el trabajo de los competidores.

Bibliómetra: -Sí, pero ya lo dijimos, no hay ningún indicador perfecto, todos tienen algún defecto, ninguno es inmaculado, por eso siempre se deben tener en cuenta las restricciones inherentes a este tipo de análisis y ser muy prudentes con las interpretaciones...

Estas últimas palabras van acompañadas de una mirada llena de reproche hacia el evaluador y el político, que se estaban repartiendo un trozo de tarta.

Evaluador: -Siempre los mismos reproches, y las mismas advertencias que son sólo aproximaciones, y ayudan a hacer preguntas, pero no a dictar sentencias....

Político: -Nosotros necesitamos también criterios cuantitativos para tomar las decisiones más justas y correctas. Los criterios cualitativos no son siempre aplicables... 
Filósofo: -Y además los cualitativos son subjetivos, que siempre pueden mejorarse al ser ampliados con datos objetivos, como son los bibliométricos...

Político: -Indudablemente significan una ayuda de gran valor, ya que se precisa de información objetiva para paliar los defectos de la evaluación por pares, aunque no se debe exagerar su uso.

Bibliómetra: -Pero prosigamos con nuestra ruta. Tras el ya comentado renacimiento de las medidas de uso, llegaron los hiperenlaces o hipervínculos en lugar de las citas...

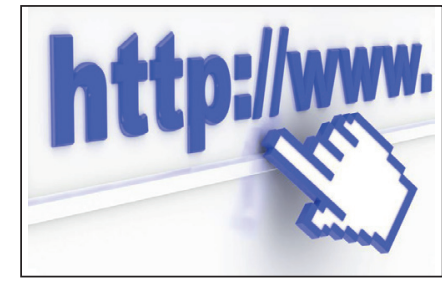

Filósofo: -Sin duda ésta ha sido una de las mayores revoluciones de los últimos siglos, y ha impactado por igual a todos los medios de comunicación.

Político: -Y la ciencia, en cierto modo, también es un medio de comunicación, por lo que también se ha visto sujeta a fuertes cambios.

Evaluador: -En ese mundo virtual los hiperenlaces retoman el papel de las citas. Además han aparecido las medidas de prestigio, cuyos indicadores se basan en la reputación de quien los produce.

Político: -Es decir que hoy podemos medir un número enorme de trazas o huellas que va dejando la publicación tanto en otras publicaciones como en ese nuevo universo del saber que es internet. Disponemos de un gran abanico de indicadores, algunos ya tradicionales y otros nuevos.

Bibliómetra: -Pero todos ellos conllevan problemas. Son indicadores muy prometedores, pero hay que asegurar algunos criterios para poder utilizarlos, como son su estabilidad, reproducibilidad, completitud, además de los serios problemas que acarrea su normalización.

Evaluador: -¿Y qué se pretende medir con ellos?

Bibliómetra: -Eso es lo más importante, su conceptualización. ¿Para qué se van a usar? ¿Qué limitaciones y restricciones implica su uso? Estas preguntas son inherentes a todos los análisis bibliométricos y son una parte esencial de ellos. Además hay que entender los diferentes escenarios que cada medida plantea.

Político: -¿Qué quiere decir con ello?

Bibliómetra: -Por ejemplo, las citas necesitan tiempo, y en algunas disciplinas esos tiempos son muy largos.

Evaluador: -Lo que está en claro contraste y crasa contradicción con el carácter de las evaluaciones, que se refieren siempre a los últimos años, ya que son éstos los que más interesan ¿verdad?

Político: -Pues claro, no nos interesa saber lo que pasó hace diez años, sino lo que está pasando en los últimos.

Bibliómetra: -Las citas a publicaciones de los años más recientes carecen de valor informativo en la mayoría de los campos científicos. Y ésta es una de las razones para el uso o mal uso del Impact Factor. No podemos medir el impacto de un artículo, sino el de la revista en que ha sido publicado; y premiar el esfuerzo de haber sido capaz de publicar en ellas, en las que la tasa de rechazo o no aceptación es muy alta debido a la gran competencia. Lo que nosotros hemos optado por llamar visibilidad para diferenciarlo del impacto.

Evaluador: -¿Y no es lo mismo para todos los indicadores?

Bibliómetra: -Pues no. Mientras las citas son como la policía que llega siempre tarde al lugar de los hechos, los indicadores de uso y las nuevas métricas se pueden recolectar muy rápidamente, y normalmente alcanzan su auge poco tiempo tras su publicación.

Científico: -iSi no se empiezan a producir incluso antes de su publicación oficial!

Filósofo: -Es decir, la información hoy en día, se empieza a consumir antes de que aparezca oficialmente.

Evaluador: -Pero pueden llegar a predecir el impacto que generaran luego en forma de citas, ¿quiere usted decir eso?

Bibliómetra: -En algunos casos, sí, pero en otros no, depende los grupos destinatarios. Ya que los usuarios o generadores de esas medidas no son los mismos que los que publican regularmente o están obligados a publicar. Piense usted en la enseñanza como parte de la academia, la industria y el gobierno...

Político: - iLa famosa triple hélice! ¡Nuestra Trinidad!

Bibliómetra: -Lo que quiero decir es que el problema es mucho más complejo de que lo muchos de ustedes piensan. Cada indicador mide o

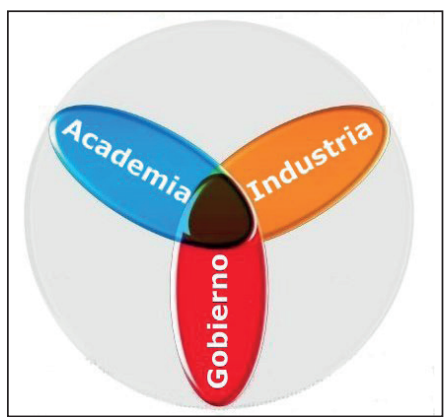
asesora un aspecto diferente y luego cada uno requiere su propio escenario.

Evaluador: -Es como si dijéramos que hay indicadores de a corto y largo plazo y que, en algunos casos, están fuertemente relacionados.

Bibliómetra: -Quiero decir que requieren diferentes condiciones y necesitan diferentes ventanas de medición, por lo que su comparación y su correlación no es siempre muy recomendable.

Filósofo: -Me parecen muy sensatas y bien fundadas sus consideraciones (dirigiéndose al Bibliómetra). Pero creo que sería también muy importante analizar su origen y su gestación. Para producir citas se requiere publicar, y esto a su vez requiere un buen esfuerzo. En cambio, los indicadores más usuales de las nuevas métricas requieren sólo un estímulo o una mera reacción, como pulsar un botón.

Evaluador: -Exactamente por eso no recomendaría yo que se comparen y menos que se aglomeren en un solo indicador.

Científico: -A propósito de indicador y ¿̇ahora qué hacemos? 
Han llegado a un cruce de caminos, donde tres señales indican diferentes direcciones. La primera indica "Acceso abierto", la segunda "Camino antiguo" y debajo "sólo con subscripción", y la tercera "Abierto pero con tasas -peaje a 50 metros".

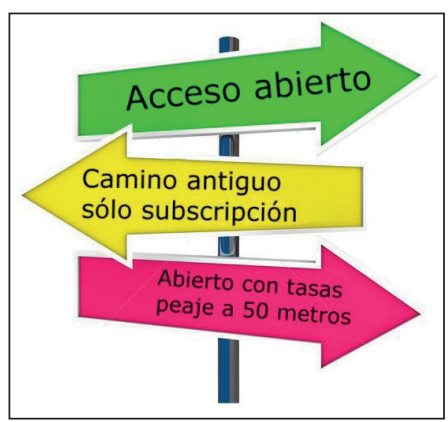

Filósofo: -Al parecer nos encontramos ante un nuevo paradigma.

Político: -Nosotros recomendamos el acceso abierto, la ciencia se financia con ingresos públicos y debe ser abierta a todos.

Evaluador: -Que sea abierto no quiere decir que sea gratis, sino que los costes los pagan los productores en lugar de los consumidores, mientras que en el camino antiguo los costes los pagan los consumidores en forma de suscripciones o licencias. La tercera posibilidad es una mezcla de las dos anteriores, pero donde por ahora pagan todos.

Bibliómetra: -Si llega a establecerse para todos, entonces sólo pagaran los costes los productores de la información. ¿Pero es eso justo? ¿Cuál es entonces la recompensa para ellos? Que uno pague por publicar sus resultados parece lógico, pero que también pague por lo que luego los otros van a utilizar... y se van a beneficiar de ello...

Filósofo: -Que la ciencia sea abierta es una meta muy elogiable, pero hay algo de utopía cuando no hipocresía en ello. Vivimos en una sociedad donde todo se compra y se vende, y que se basa sobre todo en los beneficios y ganancias. Los otros modelos no son capaces de sobrevivir.

Científico: -Lo que está claro es que la ciencia se está comercializando cada vez más. El científico se está convirtiendo en una especie de ejecutivo, con un montón de tareas que le apartan de su trabajo y le impiden desarrollar una investigación seria. Y según parece estamos obligados a producir y publicar cada vez más y más. Y lo que es peor, es que ya no se nos pide sólo que publiquemos, sino también que promocionemos nuestras publicaciones.

Bibliómetra: -Es verdad que la visibilidad no depende hoy en día ya sólo de la reputación de la revista o el medio de su publicación, sino también de cómo se ha anunciado y la promoción que se haya hecho de la revista en blogs, listas y otros medios sociales.

Científico: -El fin del científico en su papel original... o la vuelta al principio. Ese es el camino hacia donde va la ciencia: la visibilidad y la valoración de las publicaciones ya no dependen sólo de la calidad y de las revistas donde se publica, sino de su promoción y marketing.

Político: -No debemos pecar de pesimismo.
Científico: -Sí, pero alguien debería protegernos de algunos peligros, como, por ejemplo, el que éstas decisiones o acciones afecten a las personas y den lugar a una intromisión en su esfera privada. De qué manera se puede asegurar que sean conformes a la ética y no quiebren las leyes...

Filósofo: -El siguiente problema es la cantidad de datos que vamos generando. A cada segundo aparece una nueva publicación que puede generar a su vez cientos, miles o incluso más señales, ¿quién puede acaparar y entender toda esa información? Me parece que estamos perdiendo el rumbo. Dejadme otear el horizonte (y lo hace).

Evaluador: -Pero también se puede ser más positivo. Con las nuevas herramientas y los nuevos ordenadores, se pueden crear nuevas redes globales de conocimiento. Redes y máquinas a las que nosotros podemos enseñar a resolver los problemas, y luego serán ellas capaces de resolverlos por sí mismas e incluso mejor que nosotros.

Filósofo: -Es como si esas redes formaran una especie de cerebro global, o de cerebros configurados por las enseñanzas recibidas de los más sabios e inteligentes, y que serán luego capaces de resolver problemas de mayor envergadura, a mayor escala y de manera mucho más rápida. Enseñamos a las máquinas para que luego nos reemplacen y puedan superar nuestra eficacia y nuestro rendimiento.

Científico: -De eso ya estamos bastante cerca. Pero, ¿quién piensa en nosotros? Para poder rendir y ser a la vez creativos necesitamos un entorno que sea propicio. Pero la concurrencia aumenta y aumenta, está el dilema de publicar o perecer y el estar condenados a trabajar rápido y sucio. Todas estas circunstancias no son muy prometedoras, más bien lo contrario.

Evaluador: -Está claro que cuando las personas son infelices rinden menos. La motivación nace y se alimenta no sólo de buenos resultados sino de alegrías.

Filósofo: -Sí, el futuro no está sólo en las máquinas, sino en la humanidad. Lo malo es cuando dejamos de tener tiempo para leer, para hablar, para escuchar a los demás...

El filósofo se ha separado algo del grupo para ir a inspeccionar el entorno y parece haber encontrado algo verdaderamente especial, por lo nervioso y excitado que vuevle al grupo.

Filósofo: -Venid, mirad, tenéis que venir a ver esto.

Y les lleva a un alto de la jungla desde el que se puede ver a lo lejos una especie de ruina.

Filósofo: -¿¿Lo veis vosotros también o son imaginaciones mías?

E: -Son como unas ruinas. ¿Y qué pensáis vosotros que puedan simbolizar?

Político: -No era ahí exactamente a dónde queríamos llegar.

Filósofo: -Parecen como la torre de Babel, ¿̇os acordáis?

P: -iQuién no se va a acordar!

F: - Pues a mí, me parece una seria advertencia... 